\title{
Empirical Study of the Knowledge Innovation Efficiency of Universities in Different Regions of China: Panel Data Analysis Based on $\mathrm{mSBM}^{*}$
}

\author{
Xuefeng $\mathrm{Li}^{1}$ \\ Chongqing University \\ Guangming Yang ${ }^{3}$ \\ Chongqing University of Technology
}

\author{
Zhi $\mathrm{Li}^{2}$ \\ Chongqing University
}

Dalai $\mathrm{Ma}^{4}$

Chongqing University of Technology

\begin{abstract}
In this paper, the method of minimum distance to the strong frontier is adopted to research the knowledge innovation efficiency of universities in 30 provinces of China during 2005-2015. The greatest strength of this method is that, to a decision-making unit under estimation, improvements in input or output are minimized to reach the cutting edge of production. According to research findings, a significant difference exists in the knowledge innovation efficiency of universities among provinces in China. Provinces with a high efficiency are mostly distributed in the eastern coastal region and provinces with a low efficiency in the hinterland of central and western regions. Judging from region, the efficiency in the eastern region is the highest; the efficiency in the central region is the second highest; the efficiency in the western region is the lowest. Judging from contribution to inefficiency, the contribution to inefficiency made by Human input, Capital input, and technology service declines but the contribution to inefficiency made by paper output and achievement assessment improves. While China practice the plan of revitalizing education, it will focus on the following 5 provinces: Guangxi, Inner Mongolia, Guizhou, Gansu, Qinghai. In addition, in the long run, the gap between different provinces has a tendency to be narrowed in the knowledge innovation efficiency of universities.
\end{abstract}

\section{Keywords}

Knowledge Innovation Efficiency of Universities $\bullet$ mSBM Model $\bullet$ Cluster Analysis • Kernel Density Analysis

\footnotetext{
* The work was supported by Humanities and social science research project of Chongqing Municipal Education Commission (17SKG146) and the National Social Science Foundation (16BGL122).

${ }^{1}$ Correspondence to: Xuefeng Li (PhD), School of Public Affairs, Chongqing University, Chongqing 400044, China. Email: forfamilylee@163.com

${ }^{2}$ School of Public Affairs, Chongqing University, Chongqing 400044, China. Email: lizhi9999@ 126.com

${ }^{3}$ School of Management, Chongqing University of Technology, Chongqing 400054, China. Email: yangguangming@cqut.edu.cn

${ }^{4}$ School of Management, Chongqing University of Technology, Chongqing 400054, China. Email: madalai@ 163.com
}

Citation: Li, X.F., Li, Z., Yang, G.M., Ma, D.L. (2018). Empirical Study of the Knowledge Innovation Efficiency of Universities in Different Regions of China: Panel Data Analysis Based on mSBM*. Educational Sciences: Theory \& Practice, 18(5), 1087-1100. http://dx.doi.org/10.12738/estp.2018.5.011 
The $21^{\text {st }}$ century is the time of knowledge-based economy when institutions of higher education play a significant role in national innovation-driven development strategy as one of the important subjects of knowledge innovation. In particular, the universities owning a relaxed environment for innovation, a good talent pool, rich scientific research data, and intersecting sciences play an incomparable role in the knowledge innovation system (Li, Qi \& Hou, 2007; Lv, Zeng \& Gu, 2014). In the traditional education system, however, people focus more on the things brought by knowledge such as the number of science and technology projects and the technology transfer revenue and neglect the knowledge innovation efficiency of universities very much. The knowledge innovation efficiency, in fact, is the key issue universities face in innovation management and in scientific research. In the "13th Five-Year Plan" National Technological Innovation Planning the State Council issued in 2016, it is also put forward that, in the face with the existing ideological, institutional obstacles of innovation-driven development as well as the not high overall efficiency of innovation system, we should bring into full play the basic and vital role of institutions of higher education and improve their innovation level starting with the collaborative innovation in personnel training, discipline construction, research \& development, social service, etc.

Currently, China is paying more and more attention to technological innovation. Especially, attention paid to technological funds has a tendency to increase year by year. Data show that in 2010 the proportion of R\&D funds to China's gross domestic product (GDP) was $1.75 \%$, which had increased to $2.10 \%$ by 2015 , and the innovation patent owning amount per ten thousand people increased from 1.7 in 2010 to 6.3 in 2015 . As indicated by Compilation of Science \& Technology Statistics of the Institutions of Higher Education, in 2005 Chinese universities' technological funds were RMB 36.086 billion, which had increased to RMB 130.222 in 2015. Over a decade, universities' fund investment in technology service increased by 3.61 times and continues to present a good trend of increase. Now, however, in the whole technological innovation system nationwide, local universities' innovation resource allocation is always weak Therefore, evaluating the knowledge innovation of institutions of higher education scientifically and reasonably to enhance and optimize universities' innovation resource allocation not only helps the administration of universities to examine their research status in an objective and impartial manner but also provides the basis for local universities making decisions to improve scientific research management, which is significant to improvement of universities' overall innovation capability.

\section{Literature}

Evaluating universities' knowledge innovation capability on an impartial and reasonable basis is favourable for mobilizing universities' initiative to accumulate knowledge and building technological innovation-oriented universities. The knowledge innovation performance evaluation, referring to the scientific and reasonable indexes, criteria, and method of performance evaluation the scientific research management department of universities use, can evaluate the achievement in quantity, quality and efficiency universities can make with regard to paper, patent and technology transfer revenue by inputting a certain amount of human resources, financial resources, and material resources. Although the outlay of universities' technological funds is part of the government's public finance expenditure, it has different characteristics. Currently, scholars' research into 
the knowledge innovation performance of the institutions of higher education is mainly concentrated in the indexes, method, and object of performance evaluation.

As a general rule, the knowledge innovation efficiency evaluation system should have the following 3 principles: ample supply of human resources and material resources; effective allocation of innovation resources; fair allocation of innovation resources. Koksal \& Nalcaci (2006) established an evaluation index system, including employee salary, number of students, number of papers and technology transfer revenue, and used it to evaluate the knowledge innovation efficiency of 14 departments of one university in Turkey. Bonaccorsi, Daraio \& Simar (2006) established an evaluation index system in terms of human input, financial input and material input and used it to analyze the knowledge innovation performance of local universities in Italy. Johnes and Yu (2008) evaluated the scientific research input-output efficiency of 109 regular universities of China and studied the scientific research input from the number of teachers and students engaged in teaching activities and the capital input. Agasisti, Dal \& Landoni, (2011) adopted the empirical approach to analyze the academic efficiency in Italy and found that people could study the scientific research input from human resources, financial resources, and infrastructure and could analyze the related efficiency. Ahn, Charnes \& Cooper, (1988) analyzed the scale efficiency and technical efficiency of 161 American schools empirically by establishing an input-output index system consisting of staff funds, capital outlay, running expenses, number of graduates, number of postgraduates, and scientific research income.

At present, more and more scholars adopt the DEA method to analyze the knowledge innovation efficiency of universities. Chalos \& Cherian (1995) adopted the DEA method to evaluate the knowledge innovation efficiency of universities in order to avoid excessively onerous modelling. Abbott \& Doucouliagos (2003) adopted the DEA method to estimate the teaching and scientific research output efficiency of Australian universities and found that the efficiency of Australian universities was relatively high but remained to be improved. Worthington \& Lee (2008) adopted Malmquist exponent dynamic measurement method to analyze the scientific research efficiency of Australian universities in 1998-2003 and found the efficiency improved by $3.3 \%$ every year. Johnes (2006) adopted the DEA method to estimate the research innovation efficiency of more than 100 British universities and found most of British universities have a high technical efficiency and high scale efficiency. Ruggiero, Miner \& Blanchard (2002) considered that, despite the widely application in education evaluation, the DEA model produces an error when analyzing cross-sectional data and produces no error when analyzing panel data, according to the simulation result.

In China, literature now is more focused on evaluating the higher education efficiency than focused on analyzing the knowledge innovation efficiency of provincial universities. Guo (2003) built a science \&technology effectiveness evaluation model based on the DEA method as well as 9 disciplines and found a difference existing in the input-output efficiency between disciplines. Lu \& Liu (2006) selected the humanities and social sciences of 68 universities directly under the Ministry of Education in 2000-2003 as the research object. As indicated by the evaluation result, the efficiency of these disciplines presents a trend of increasing year by year but remains to be improved in general. $\mathrm{Ha} \& \mathrm{Li}$ (2010) selected the humanities and social sciences at universities as the research object and adopted the AHP method in combination with the DEA method to evaluate the scientific research efficiency. As indicated by the evaluation result, of all universities being 
evaluated, the ones with a good technical efficiency and good scale efficiency are $45 \%$; the ones with non-DEA efficiency of humanities are 45\%. Jiang \& Wang (2009) selected the management science of " 985 " universities as the research object and evaluated the knowledge innovation efficiency. As indicated by the evaluation result, the items of research input should be as many as possible and be capable to reflect the evaluation content.

All in all, current indexes used to evaluate the knowledge innovation efficiency of universities are categorized into 4 groups: basic indexes, common development indexes, personality development indexes and knowledge innovation performance indexes. Performance evaluation methods include the input-output method, analytic hierarchy process, benchmarking method, balanced scorecard, Tobit model, total factor productivity (TFP) exponential method, stochastic regression analysis method and data envelopment analysis (DEA) method. Especially the last two methods are the most commonly used by scholars who analyze the knowledge innovation efficiency. The combination of two or more methods becomes a new trend in efficiency evaluation. Most scholars select the same discipline or department of different schools as the evaluation object but attach little importance to the knowledge innovation efficiency of universities in different provinces or regions. There is a difference between regions in both the number and the knowledge innovation efficiency of Chinese universities. In order to make full use of limited innovation resources and allocate these resources reasonably, an empirical study and a comparative study of the knowledge innovation efficiency of universities are so important.

\section{Purpose}

In the research, minimum distance to the strong frontier is used to measure the knowledge innovation efficiency of provincial universities. The greatest advantage of the mSBM method is that in the process of measuring efficiency, the variable cost of improving efficiency optimization is the smallest. This method is the most advanced method currently used for evaluating efficiency. In general, this research consists of four stages, namely Needs Analysis, Measurement Method, Index system and Evaluation. In general, can be described below:

First of all, through the collection of relevant literature at home and abroad, this study summarizes the shortcomings of the existing literature on the evaluation method, index design and research area of knowledge innovation efficiency in universities. Combining with the low resource allocation of knowledge innovation in Chinese universities, the paper points out the importance of evaluating the level of knowledge innovation objectively.

Secondly, by comparing the two methods of SBM and mSBM, we can get the advantage of using mSBM. Applying this method to evaluate the knowledge innovation efficiency of universities can not only improve the accuracy of measurement, but also save the variable cost expenditure of managers and decision makers.

Thirdly, this paper designs an evaluation system for the efficiency of knowledge innovation in Colleges and universities, which includes the input of human and capital, the output of paper, technology service and achievement assessment. Scientific and reasonable evaluation index system is the premise of accurately measuring the level of knowledge innovation in universities. 
Finally, on the basis of using mSBM to measure the knowledge innovation efficiency of university, this paper uses Input-Output Invalidity Analysis, Cluster Analysis and Kernel Density Estimation to carry out a comprehensive evaluation of knowledge innovation efficiency of university, and draws important enlightenment for the relevant discussion.

\section{Method}

\section{mSBM Model}

Using the research findings of Jahanshahloo, Vakili \& Zarepisheh (2012) and Aparicio, Ruiz \& Sirvent (2007) for reference, this paper proposes the method of minimum distance to the cutting edge of high efficiency, improving the traditional SBM model further. This method determines the projection point on the cutting edge of production by minimizing $\mathrm{L}_{1}$ so as to estimate the efficiency. On this basis, the method of minimum distance to the cutting edge of high efficiency, including undesirable output, was proposed. Suppose there are $\mathrm{n}$ decisionmaking units in a production system, and m production factors are inputted to each decision-making unit, producing $s_{1}$ desirable outputs and $s_{2}$ undesirable outputs. Suppose that vectors $\mathrm{X}=\left(\mathrm{x}_{1}, \mathrm{x}_{2}, \ldots, \mathrm{x}_{\mathrm{n}}\right) \in \mathrm{R}_{+}^{\mathrm{m} \times \mathrm{n}}$, $\mathrm{Y}^{\mathrm{g}}=\left(\mathrm{y}_{1}^{\mathrm{g}}, \mathrm{y}_{2}^{\mathrm{g}}, \ldots, \mathrm{y}_{\mathrm{n}}^{\mathrm{g}}\right) \in \mathrm{R}_{+}^{\mathrm{s}_{1} \times \mathrm{n}}, \mathrm{Y}^{\mathrm{b}}=\left(\mathrm{y}_{1}^{\mathrm{b}}, \mathrm{y}_{2}^{\mathrm{b}}, \ldots, \mathrm{y}_{\mathrm{n}}^{\mathrm{b}}\right) \in \mathrm{R}_{+}^{\mathrm{S}_{2} \times \mathrm{n}}$ represent the variables factor input, desirable output and undesirable output respectively, expressed by $\mathrm{P}(\mathrm{x})=\{(\mathrm{x}, \mathrm{y}): \mathrm{x}$ can produces $\mathrm{y}\} . \mathrm{F}^{\mathrm{S}}(\mathrm{P})$ is the value in the possible set to the cutting edge of high efficiency?

On the premise that $\mathrm{L}_{1}$ is minimized, the model based on the method of minimum distance to the cutting edge of high efficiency is expressed as follows:

$$
\begin{aligned}
& (\operatorname{mSBM}) \min \left(\sum_{\mathrm{i}=1}^{\mathrm{m}} \mathrm{s}_{\mathrm{i} 0}^{-}+\sum_{\mathrm{r}=1}^{\mathrm{s}_{1}} \mathrm{~s}_{\mathrm{r} 0}^{+}+\sum_{\mathrm{l}=1}^{\mathrm{s}_{2}} \mathrm{~s}_{\mathrm{l0}}^{-}\right)+\mathrm{M}\left(\sum_{\mathrm{i}=1}^{\mathrm{m}} \mathrm{s}_{\mathrm{i} 0}^{-}+\sum_{\mathrm{r}=1}^{\mathrm{s}_{1}} \mathrm{~s}_{\mathrm{r} 0}^{+}+\sum_{\mathrm{l}=1}^{\mathrm{s}_{2}} \mathrm{~s}_{\mathrm{l0}}^{-}\right) \\
& \mathrm{s}_{\mathrm{i} 0}^{-} \geq 0, \mathrm{i}=1, \ldots, \mathrm{m} \\
& \mathrm{s}_{\mathrm{r} 0}^{+} \geq 0, \mathrm{r}=1, \ldots, \mathrm{s}_{1}, \mathrm{~s}_{\mathrm{l0}}^{-} \geq 0, \mathrm{i}=1, \ldots, \mathrm{s}_{1}, \max \left(\sum_{\mathrm{i}=1}^{\mathrm{m}} \overline{\mathrm{s}}_{\mathrm{i} 0}^{-}+\sum_{\mathrm{r}=1}^{\mathrm{s}_{1}} \overline{\mathrm{s}}_{\mathrm{r} 0}^{+}+\sum_{\mathrm{l}=1}^{\mathrm{s}_{2}} \overline{\mathrm{s}}_{10}^{-}\right) \\
& \text {s.t. } \sum_{\mathrm{j} \in \mathrm{E}_{\mathrm{C}}} \lambda_{\mathrm{j}} \mathrm{x}_{\mathrm{ij}}+\overline{\mathrm{s}}_{\mathrm{i} 0}^{-}=\mathrm{x}_{\mathrm{i} 0}-\mathrm{s}_{\mathrm{i} 0}^{-} \\
& \sum_{\mathrm{j} \in \mathrm{E}_{\mathrm{C}}} \lambda_{\mathrm{j}} \mathrm{y}_{\mathrm{ij}}^{\mathrm{g}}-\overline{\mathrm{s}}_{\mathrm{r} 0}^{+}=\mathrm{y}_{\mathrm{i} 0}^{\mathrm{g}}+\mathrm{s}_{\mathrm{r} 0}^{+}, \sum_{\mathrm{j} \in \mathrm{E}_{\mathrm{C}}} \lambda_{\mathrm{j}} \mathrm{y}_{\mathrm{ij}}^{\mathrm{b}}+\overline{\mathrm{s}}_{\mathrm{l0}}^{-}=\mathrm{y}_{\mathrm{i} 0}^{\mathrm{b}}-\mathrm{s}_{\mathrm{l0}}^{-}, \lambda_{\mathrm{j}} \geq 0, \overline{\mathrm{s}}_{\mathrm{i} 0}^{-} \geq 0, \overline{\mathrm{s}}_{\mathrm{r} 0}^{+} \geq 0, \overline{\mathrm{s}}_{\mathrm{l0}}^{-} \geq 0
\end{aligned}
$$

In Formula (1), $\mathrm{s}_{\mathrm{i} 0}^{-}, \mathrm{s}_{\mathrm{ro}}^{+}, \mathrm{s}_{10}^{-}, \overline{\mathrm{s}}_{\mathrm{i} 0}^{-}, \overline{\mathrm{s}}_{\mathrm{r} 0}^{+}, \overline{\mathrm{s}}_{\mathrm{l} 0}^{-}$represent slack variables; $\mathrm{M}$ represents a large positive number. The combination of Formulas (1) and (3) is a typical bi-level linear programming, i.e., the method of minimum distance to the cutting edge of high efficiency or the minimum distance SMB method (mSBM) we call. This bilevel linear programming is called mSBM for it evolves from the SMB model through optimization. If Formula (2) changes to:

$$
\min \left(\frac{1-\frac{1}{\mathrm{~m}} \sum_{\mathrm{i}=1}^{\mathrm{m}} \overline{\mathrm{s}}_{\mathrm{i0}}^{-} / \mathrm{x}_{\mathrm{i} 0}}{1+\frac{1}{\mathrm{~s}_{1}+\mathrm{s}_{2}}\left(\sum_{\mathrm{r}=1}^{s_{1}} \overline{\mathrm{s}}_{\mathrm{r} 0}^{+} / \mathrm{y}_{\mathrm{r} 0}+\sum_{\mathrm{l}=1}^{s_{2}} \overline{\mathrm{s}}_{\mathrm{l0}}^{-} / \mathrm{b}_{\mathrm{l0}}\right)}\right)
$$

Then Formula (1) combines with Formula (3) to form another bi-level linear programming, i.e., the SBM model. This model cannot be realized unless the values of $\sum_{\mathrm{i}=1}^{\mathrm{m}} \overline{\mathrm{s}}_{\mathrm{i} 0}^{-} / \mathrm{x}_{\mathrm{i} 0}, \sum_{\mathrm{r}=1}^{\mathrm{s}_{1}} \overline{\mathrm{s}}_{\mathrm{r} 0}^{+} / \mathrm{y}_{\mathrm{r} 0}, \sum_{\mathrm{l}=1}^{\mathrm{s}_{2}} \overline{\mathrm{s}}_{10}^{-} / \mathrm{b}_{10}$ are maximum. Generally speaking, the denominator is a constant number in each of these three formulae, so the 
value of Formula (3) constraining the SBM model is the minimum if the slack variables $\overline{\mathrm{s}}_{\mathrm{i} 0}^{-}, \overline{\mathrm{s}}_{\mathrm{r} 0}^{+}, \overline{\mathrm{s}}_{\mathrm{l0}}^{-}$are as large as possible. Compared with the SBM model, the greatest strength of $\mathrm{mSBM}$ is that the minimum improvement of input or output is needed to make the efficiency reach the cutting edge of production. For this reason, the mSBM model is very practical in estimating the knowledge innovation efficiency of regional universities.

\section{Valuation index System}

Efficiency consists of input and output and it refers to the degree of input being converted into output, i.e. input-output ratio. An organized activity means converting input into output, where output is the specific measure meteorological item to achieve the organizational goal and input is the resource of output. The knowledge innovation efficiency of universities estimated based on the DEA method requires that the selection of input and output indexes follow some principles in order to evaluate the efficiency of each decision-making unit effectively.

Universities' knowledge innovation is a multi-input multi-output complex process where the innovation subject of universities produces the intangible scientific knowledge and tangible research papers, reports, proprietary products, etc. by means of modernized experiments through special thinking activities in the brain (Lu et al., 2005). From the knowledge innovation input and output of research institutes and enterprises, it has the following differences: First, innovation subjects are mostly the scientists engaged in teaching and scientific research, and the number and level of teachers engaged in scientific research are the major factors influencing the knowledge innovation capability and performance of universities (Hu, 2014). Second, the majority of universities' technological funds are from the financial funds allocated by the central government and the local governments; a small part is from universities' self-financing. Third, the research field includes applied research, basic research, and frontier scientific research. Fourth, innovation output includes scientific knowledge and high-level papers, monographs, patents, new products, etc. (Wu et al., 2008).

Table 1

Indexes for Evaluating the Knowledge Innovation Efficiency of the Institutions of Higher Education

\begin{tabular}{lll}
\hline Classification & \multicolumn{1}{c}{ Specific index } & \multicolumn{1}{c}{ Explanation } \\
\hline \multirow{2}{*}{ Input indexes } & $\begin{array}{l}\text { Human input } \\
\text { Capital input }\end{array}$ & $\begin{array}{l}\text { In-service teaching and research staff at universities (in people) } \\
\text { Outlay of universities' technological funds (in RMB10,000) } \\
\text { Number of high-level journal articles published by universities } \\
\text { Output indexes }\end{array}$ \\
& $\begin{array}{l}\text { Paper output } \\
\text { Technology service } \\
\text { achievement } \\
\text { assessment }\end{array}$ & $\begin{array}{l}\text { Technology transfer revenue of universities (in RMB10,000) } \\
\text { Number of award-winning achievements made by universities } \\
\text { (in items) }\end{array}$ \\
\hline
\end{tabular}

Based on related study, we established the principles for the knowledge innovation efficiency input/output index system of universities, taking into account comprehensiveness, estimableness, simplicity, operability as well as data availability, and finally determined the input and output indexes for knowledge innovation of universities. Among them, input indexes involve two aspects: human input and financial input; output indexes involve three aspects: paper output, technology service and achievement assessment. The table below shows the meaning of specific index of each input/output variable. 


\section{Data source}

To satisfy the basic requirement for data use, in view of data availability, this paper takes the panel data in 30 provinces of China during 2005-2015 as the research object. Since the absence of data for multiple consecutive years in Tibet does not reach the basic standard for study, Tibet is rejected from the gross sample. Through data screening, all data used in this paper are from authoritative yearbooks such as Compilation of Science \& Technology Statistics of the Institutions of Higher Education of China (2006-2016), China Statistical Yearbook and local statistical yearbooks.

\section{Results}

\section{Comparison of the knowledge innovation efficiency of universities between different regions}

Based on the mSBM model, we calculated the knowledge innovation efficiency of universities in 30 provinces of China during 2005-2015 using software DEA, and the calculation results are given in Table 2. Judging from the average knowledge innovation efficiency of universities in each province, the top 5 provinces are respectively Jiangsu, Beijing, Shanghai, Henan and Chongqing with an average value above 0.95. They all say at the cutting edge close to the production function. Among the rest, Jiangsu, Beijing and Shanghai are located in the eastern region. In these 3 provinces, marketization reaches a high degree; education combines with science \&technology tightly; there are rich technological resources; knowledge output is relatively ideal; the development of knowledge innovation capability has stepped in a benign cycle; the university knowledge innovation model is relatively mature. Henan is located in the central region of China. It has a high knowledge innovation efficiency of universities because Henan, as a big traditional province of education in China, has plenty of universities as well as researchers. Chongqing, as the only one municipality directly under the Central Government in the western region, has a high knowledge innovation efficiency of universities, too because it enjoys lots of national preferential policies in terms of scientific research and education. The bottom 5 provinces are respectively Guangxi, Guizhou, Inner Mongolia, Gansu and Qinghai with an average value below 0.75. This also suggests the lack of technological resources of universities in these regions. On one hand, the size of university knowledge input is limited. On the other hand, the knowledge innovation efficiency is low and the input-output and efficiency are asymmetric. Thus, it can be seen that a significant difference exists between provinces in the knowledge innovation efficiency of Chinese universities. Provinces with a high efficiency are mostly distributed in the eastern coastal region and provinces with a low efficiency mostly in the hinterland of central and western regions. 
Li, Li, Yang, Ma / Empirical study of the knowledge innovation efficiency of universities in different regions

Table 2

Knowledge Innovation Efficiency of Universities in Each Province During 2005-2015

\begin{tabular}{|c|c|c|c|c|c|c|c|c|c|c|c|c|}
\hline Province & 2005 & 2006 & 2007 & 2008 & 2009 & 2010 & 2011 & 2012 & 2013 & 2014 & 2015 & Average \\
\hline Jiangsu & 1 & 1 & 0.941 & 0.999 & 1 & 1 & 1 & 1 & 1 & 0.999 & 0.939 & 0.989 \\
\hline Beijing & 1 & 1 & 1 & 1 & 0.813 & 1 & 1 & 1 & 1 & 1 & 1 & 0.983 \\
\hline Shanghai & 1 & 1 & 0.734 & 1 & 1 & 1 & 1 & 1 & 1 & 1 & 1 & 0.976 \\
\hline Henan & 1 & 1 & 1 & 1 & 1 & 1 & 0.814 & 1 & 0.893 & 1 & 1 & 0.973 \\
\hline Chongqing & 0.795 & 1 & 1 & 0.962 & 0.969 & 1 & 1 & 1 & 0.902 & 0.961 & 1 & 0.963 \\
\hline Tianjin & 1 & 1 & 1 & 1 & 1 & 1 & 0.618 & 1 & 0.926 & 1 & 0.843 & 0.944 \\
\hline Shandong & 1 & 1 & 0.986 & 0.929 & 1 & 0.909 & 1 & 0.895 & 0.936 & 0.858 & 0.811 & 0.938 \\
\hline Ningxia & 1 & 1 & 0.745 & 1 & 0.269 & 1 & 1 & 1 & 1 & 1 & 1 & 0.91 \\
\hline Anhui & 0.817 & 0.858 & 0.896 & 0.885 & 0.847 & 0.876 & 0.881 & 1 & 1 & 1 & 0.908 & 0.906 \\
\hline Hebei & 0.945 & 0.891 & 0.9 & 0.885 & 0.879 & 0.901 & 1 & 0.922 & 0.862 & 0.866 & 0.9 & 0.905 \\
\hline Shaanxi & 1 & 1 & 1 & 0.966 & 0.943 & 0.911 & 0.657 & 0.629 & 0.933 & 0.945 & 0.95 & 0.903 \\
\hline Xinjiang & 0.665 & 0.694 & 1 & 1 & 1 & 0.951 & 0.646 & 0.982 & 1 & 1 & 1 & 0.903 \\
\hline Sichuan & 0.82 & 0.866 & 1 & 1 & 0.916 & 1 & 0.559 & 1 & 0.773 & 0.955 & 1 & 0.899 \\
\hline Hunan & 0.883 & 0.895 & 0.912 & 0.856 & 0.877 & 0.864 & 0.876 & 0.913 & 0.941 & 0.939 & 0.847 & 0.891 \\
\hline Yunnan & 1 & 1 & 1 & 0.842 & 0.782 & 0.844 & 0.834 & 0.778 & 0.895 & 0.797 & 1 & 0.888 \\
\hline Zhejiang & 0.979 & 0.78 & 1 & 0.975 & 0.931 & 0.927 & 0.72 & 0.88 & 0.866 & 0.785 & 0.75 & 0.872 \\
\hline Guangdong & 1 & 0.82 & 0.871 & 0.871 & 0.844 & 0.928 & 0.643 & 0.915 & 0.753 & 0.869 & 0.832 & 0.85 \\
\hline Hubei & 0.952 & 0.997 & 1 & 0.852 & 0.799 & 0.723 & 0.635 & 0.839 & 0.789 & 0.791 & 0.964 & 0.849 \\
\hline Jilin & 0.918 & 0.758 & 0.83 & 0.919 & 0.312 & 0.94 & 0.844 & 1 & 0.92 & 0.859 & 1 & 0.846 \\
\hline Jiangxi & 0.6 & 1 & 1 & 1 & 0.744 & 0.738 & 0.749 & 0.805 & 0.703 & 0.946 & 0.902 & 0.835 \\
\hline Fujian & 0.8 & 0.527 & 0.849 & 0.911 & 1 & 0.849 & 0.817 & 0.831 & 0.834 & 1 & 0.647 & 0.824 \\
\hline Hainan & 1 & 0.56 & 0.79 & 0.809 & 0.507 & 1 & 0.657 & 1 & 1 & 1 & 0.709 & 0.821 \\
\hline Liaoning & 0.939 & 0.815 & 0.801 & 0.809 & 0.856 & 0.8 & 0.718 & 0.944 & 0.71 & 0.713 & 0.838 & 0.813 \\
\hline Shanxi & 0.914 & 0.637 & 0.966 & 0.832 & 0.697 & 0.808 & 0.709 & 0.747 & 0.686 & 0.688 & 0.917 & 0.782 \\
\hline Heilongjiang & 0.578 & 0.538 & 0.804 & 0.747 & 0.642 & 0.734 & 0.868 & 0.863 & 0.868 & 0.871 & 0.801 & 0.756 \\
\hline Guangxi & 0.67 & 0.413 & 0.736 & 0.691 & 0.83 & 0.883 & 0.717 & 0.782 & 0.87 & 0.658 & 0.912 & 0.742 \\
\hline Guizhou & 0.63 & 0.273 & 0.804 & 0.753 & 0.394 & 0.555 & 0.588 & 0.783 & 0.695 & 0.813 & 0.885 & 0.652 \\
\hline Inner Mongolia & 0.602 & 0.513 & 0.673 & 0.846 & 0.77 & 0.819 & 0.396 & 0.705 & 0.306 & 0.205 & 0.9 & 0.612 \\
\hline Gansu & 0.963 & 0.333 & 1 & 0.795 & 0.477 & 0.554 & 0.438 & 0.265 & 0.197 & 0.434 & 0.888 & 0.577 \\
\hline Qinghai & 0.265 & 0.224 & 0.297 & 0.39 & 0.284 & 0.604 & 0.361 & 0.71 & 0.498 & 0.455 & 0.555 & 0.422 \\
\hline
\end{tabular}


Figure 1 also demonstrates the significant differences in Efficiency of knowledge innovation in Universities among the major regions of China: eastern, western (East China includes Beijing, Tianjin, Hebei, Shanghai, Jiangsu, Zhejiang, Fujian, Shandong, Guangdong, Hainan, Liaoning; Central China includes Shanxi, Jilin, Heilongjiang, Anhui, Jiangxi, Henan, Hubei, Hunan; West China includes Inner Mongolia, Guangxi, Chongqing, Sichuan, Guizhou, Yunnan, Tibet, Shaanxi, Gansu, Qinghai, Ningxia, Xinjiang.), and central. Judging from the average knowledge innovation efficiency of universities, the average value in the eastern region is up to 0.9013 , above the average value nationwide 0.841 ; the average value in the central region is up to 0.855 , above the average value nationwide 0.841 ; but the average value in the western region is merely 0.770 , apparently below the average value nationwide. Thus, it can be seen that the knowledge innovation efficiency of universities is significantly different among three major regions of China. The efficiency in the eastern region is the highest; the efficiency in the central region is the second highest; the efficiency in the western region is the lowest. Accordingly, in the central and western regions backward in terms of knowledge innovation capability, the government need improve the knowledge input in the backward areas through regional allocation and policy support as well as reform the existing science \& technology management system of universities, striving to promote the knowledge innovation efficiency.

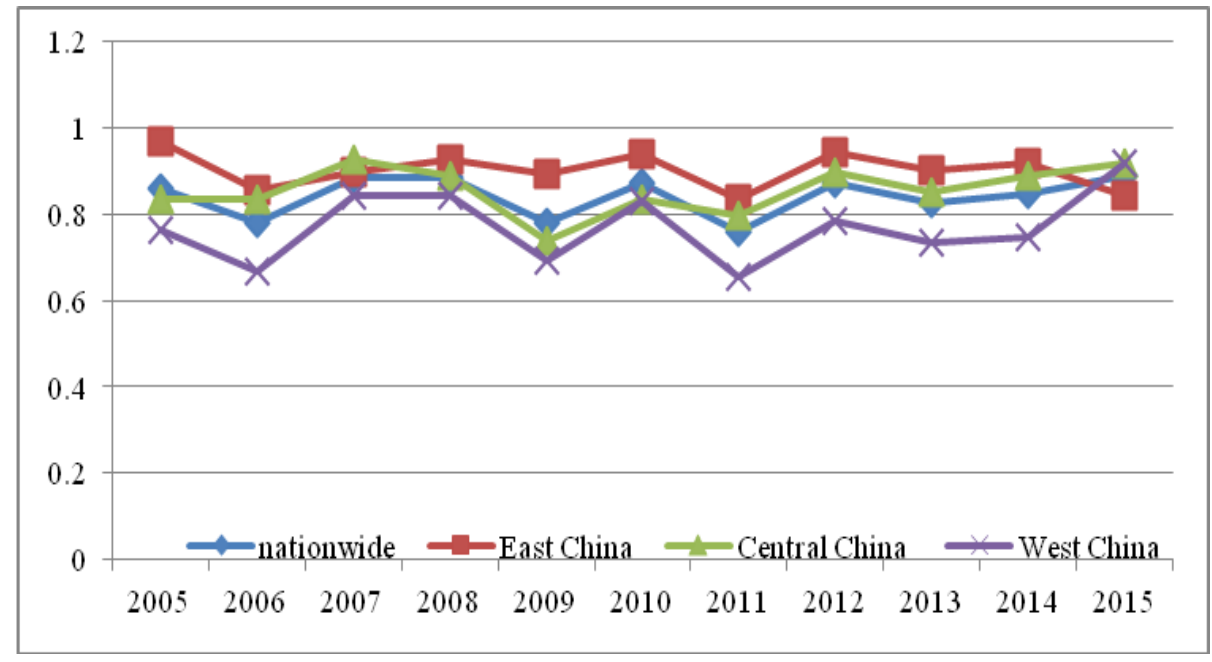

Figure 1. Knowledge innovation efficiency of universities throughout nationwide and three major regions of China

\section{Inefficiency analysis of the knowledge innovation of universities}

Table 3 gives the percentage of efficiency improvement and the rate of contribution to inefficiency in the bottom 5 provinces with regard to the average knowledge innovation efficiency of universities in 2005 and 2015. It can be seen that the input/output efficiency improvement in each province changes much from the year 2005. Taking Guangxi for example, in 2005 the major inefficient item is capital input; but in 2015 the major 
inefficient item changes to achievement assessment. Taking Inner Mongolia as another example, both in 2005 and in 2015 the efficiency loss is mostly caused by too much human input. Judging from the average value in 5 provinces, the contribution to inefficiency made by Human input, Capital input, and technology service declines; but the contribution to inefficiency made by paper output and achievement assessment climbs.

Table 3

Percentage of Efficiency Improvement and Rate of Contribution to Inefficiency in Major Provinces

\begin{tabular}{|c|c|c|c|c|c|c|c|c|c|}
\hline \multicolumn{5}{|c|}{2005} & \multicolumn{5}{|c|}{2015} \\
\hline 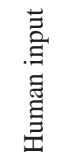 & 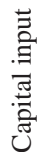 & 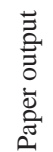 & 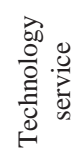 & 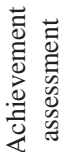 & 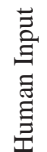 & 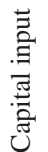 & 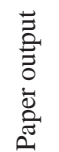 & 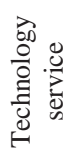 & 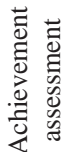 \\
\hline
\end{tabular}



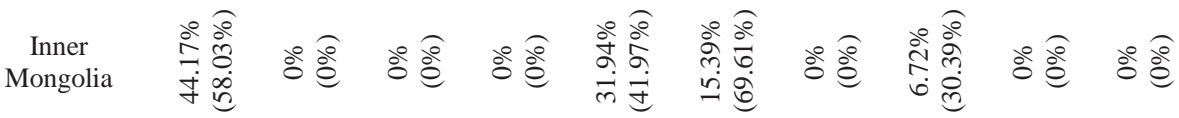

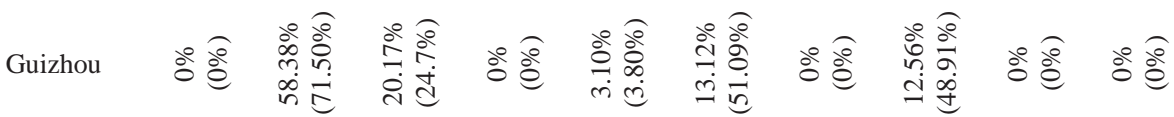

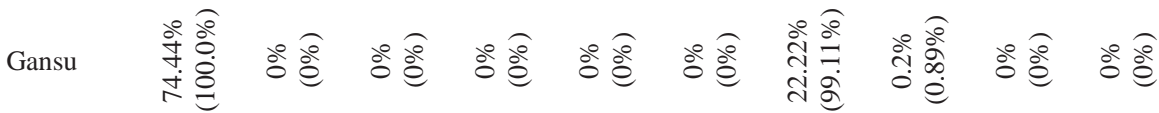

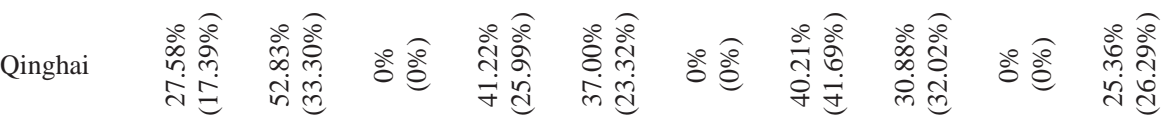

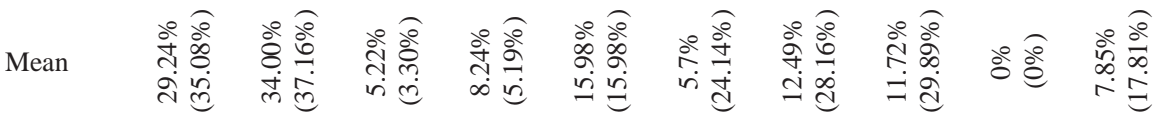

\section{Cluster analysis of the knowledge innovation efficiency of universities}

Table 4

Cluster Analysis of the Knowledge Innovation Efficiency of Universities

\section{Efficiency cluster}

High efficiency region

Medium efficiency region

Low efficiency region

\section{Regions}

Beijing, Tianjin, Hebei, Shanghai, Jiangsu, Shandong, Henan, Hunan, Chongqing, Sichuan, Yunnan, Ningxia, Xinjiang

Shanxi, Liaoning, Jilin, Heilongjiang, Zhejiang, Anhui, Fujian, Jiangxi, Hubei, Guangdong, Hainan, Shaanxi Guangxi, Inner Mongolia, Guizhou, Gansu, Qinghai 
We carried out the K-Means Cluster analysis of the knowledge innovation efficiency of universities in all provinces by means of SPSS17.0 software and divide these provinces into high efficiency region, medium efficiency region and low efficiency region. Table 4 shows the cluster analysis result. Located in the high efficiency region are 13 provinces: Beijing, Tianjin, Hebei, Shanghai, Jiangsu, Shandong, Henan, Hunan, Chongqing, Sichuan, Yunnan, Ningxia, Xinjiang; located in the medium efficiency region are 12 provinces: Shanxi, Liaoning, Jilin, Heilongjiang, Zhejiang, Anhui, Fujian, Jiangxi, Hubei, Guangdong, Hainan, Shaanxi, where the efficiency remains to be improved; located in the low efficiency region are 5 provinces: Guangxi, Inner Mongolia, Guizhou, Gansu, Qinghai, where the efficiency loss is very high, and they are the focus when China implements the plan of revitalizing education. The above indicates that provinces located in the medium efficiency region and low efficiency region are still $57 \%$ of all provinces in China. In these provinces, the knowledge innovation efficiency of universities fails to reach the cutting edge. These regions ought to be the focus of China's attention because the knowledge innovation of universities here lacks an effective automatic adjustment mechanism and are restricted by the traditional system.

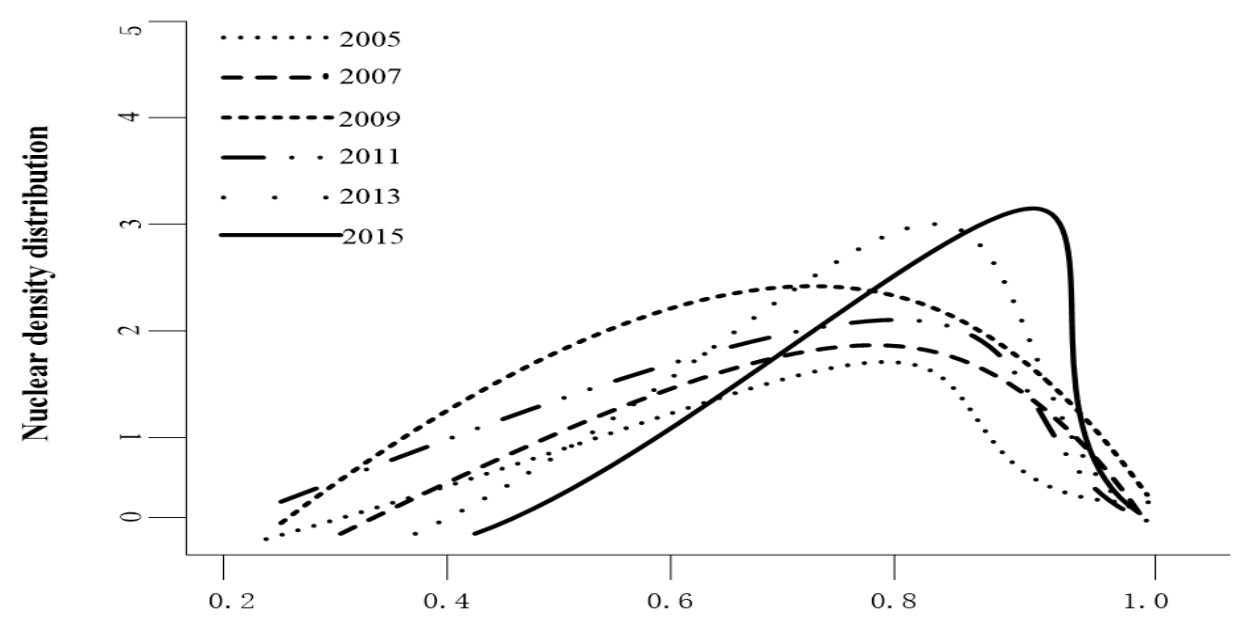

Figure 2. Kernel density distribution of the knowledge innovation efficiency of universities

\section{Convergence of the knowledge innovation efficiency of universities}

In order to investigate the dynamic convergence or divergence of the knowledge innovation efficiency of universities in China during 2005-2015, we conducted an analysis through kernel density estimation in this paper. Figure 2 shows the knowledge innovation efficiency of universities in six years: 2005, 2007, 2009, 2011, 2013 and 2015 respectively. In the figure, the horizontal axis represents the knowledge innovation efficiency of universities; the longitudinal axis represents the kernel density. The cumulative wave crest moves up and right significantly, which means the kernel density corresponding to the wave crest rises and the efficiency is increasing. It indicates that the knowledge innovation efficiency of universities in most provinces is improved to varying degrees in general. Such evolutionary kernel density distribution suggests the knowledge innovation efficiency in many regions is improved as well as means the gaps between different provinces are gradually 
shrunk. That's, provinces with a low efficiency will keep catching up with those with a high efficiency. In summary, over these 6 time periods, differences in the knowledge innovation efficiency of universities among 30 provinces tend to be reduced.

\section{Discussion}

In this paper, the method of minimum distance to the cutting edge of high efficiency, including undesirable output, is adopted to estimate the knowledge innovation efficiency of universities in 30 provinces in China. This method calculates the efficiency by minimizing $\mathrm{L}_{1}$ and getting the closest goal and the minimum distance reference point from the cutting edge of high efficiency. It is applied to analyzing the knowledge innovation efficiency of universities for the first time. Relative to the traditional analysis of knowledge innovation efficiency, the strength of this method lies in the need of a little improvement of input or output to reach the optimum. It is more in favorable for the formulation of policy recommendations.

The research suggests, among the provinces ranking top 5 in regard to the knowledge innovation efficiency of universities, Jiangsu, Beijing and Shanghai are located in the central and eastern coastal regions and Henan and Chongqing in the hinterland of central and western regions, which confirms that China's innovation resources of universities are mostly distributed in the economically developed eastern coastal region. Judging from region, the knowledge innovation efficiency of universities in the eastern and central regions are above the average value nationwide; but the knowledge innovation efficiency of universities in the western region is below the average value nationwide, outstanding the unbalanced development of regional education again. Judging from contribution to inefficiency, the contribution made by Human input, Capital input, and technology service declines; but the contribution made by paper output and achievement assessment improves. According to the cluster analysis, in 13 provinces in China, the knowledge innovation of universities is ideal; and Guangxi, Inner Mongolia, Guizhou, Gansu, and Qinghai will be the focus of attention when China implements the plan of revitalizing education. In the end, as revealed by the kernel density estimation, differences in the knowledge innovation efficiency of universities among 30 provinces are gradually reduced; provinces with a low efficiency are gradually catching up with those with a high efficiency.

\section{References}

Abbott, M., \& Doucouliagos, C. (2003). The efficiency of Australian universities: A data envelopment analysis. Economics of Education review, 22(1), 89-97. http://dx.doi.org/10.1016/S0272-7757(01)00068-1

Agasisti, T., Dal B. A., Landoni, P. E. (2011). Valuating the efficiency of research in academic departments: An empirical analysis in an Italian region. Higher Education Quarterly, 65(3), 267-289. https://doi.org/10.1111/j.1468-2273.2011.00489.x

Ahn, T., Charnes, A., \& Cooper, W. W. (1988). Some statistical and DEA evaluations of relative efficiencies of public and private institutions of higher learning. Socio-Economic Planning Sciences, 22(6), 259-269. http://dx.doi.org/10.1016/0038-0121(88)90008-0 
Aparicio, J., Ruiz, J L, \& Sirvent, I. (2007). Closest targets and minimum distance to the pareto-efficient frontier in DEA. Journal of Productivity Analysis, 28(3), 209-218. http://dx.doi.org/10.1007/s11123-007-0039-5

Bonaccorsi, A., Daraio, C., \& Simar, L. (2006). Advanced indicators of productivity of universities an application of robust nonparametric methods to Italian data. Scientometrics, 66(2), 389-410.

Chalos, P., \& Cherian, J. (1995). An application of data envelopment analysis to public sector performance measurement and accountability. Journal of Accounting and Public Policy, 14(2), 143-160. http://dx.doi.org/10.1016/0278-4254(94)00015-S

Guo, X. L. (2003). Efficiency measurement for the emphasis subjects based on DEA. Chinese Journal of Management Science, 11(6), 77-80. http://dx.doi.org/10.3321/j.issn:1003-207X.2003.06.016

Han, H. B., \& Li, Q. S. (2010). Evaluation of the Efficiency of Humanity and Social Sciences Research in Universities Based on AHP/DEA. Higher Education Development and Evaluation, 26(2), 49-56. http://dx.doi.org/10.3963/j.issn.1672-8742.2010.02.008

Hu, S. H., Du, D. B., \& You, X. J. (2014). Spatial-temporal evolution analysis on knowledge innovation performance of universities in China's "Growth Triangle Regions”. Economic Geography, 25(2), 75-79.

Jahanshahloo, G. R., Vakili, J., \& Zarepisheh, M. A. (2012). Linear bilevel programming problem for obtaining the closest targets and minimum distance of a unit from the strong efficient frontier. Asia-Pacific Journal of Operational Research, 29(2), 1-19. http://dx.doi.org/10.1142/S021759591250011X

Jiang, C. H. \& Wang, Y. Q. (2009). Empirical study on the evaluation of input-output efficiency of management subject in 985 project college. Science \& Technology Progress and Policy, 26(22), 193-196.

Johnes, J. (2006). Data envelopment analysis and its application to the measurement of efficiency in higher education. $\quad$ Economics $\quad$ of $273-288$. http://dx.doi.org/10.1016/j.econedurev.2005.02.005

Johnes, J., \& Yu, L. (2008). Measuring the research performance of Chinese higher education institutions using data envelopment analysis. China Economic Review, 19(4), 679-696. http://dx.doi.org/10.1016/j.chieco.2008.08.004

Koksal, G., \& Nalfaci, B. (2006). The relative efficiency of departments at a Turkish engineering college: a data envelopment analysis. Higher Education, 51(2): 173-189. http://dx.doi.org/10.1007/s10734-004-6380-y

Li, Q. M., Qi, Y., \& Hou, J. (2007). An evaluation strategy on the university scientific research competitiveness. China Soft Science, 22(3), 147-152. http://dx.doi.org/10.3969/j.issn.1002-9753.2007.03.023

Lu, G. S., \& Liu, L. (2003). Social Scientific Research Efficiency of Universities Directly Under the Ministry of Education of P. R. China and Its Trend. Open Education Research, 12(1), 29-35. http://dx.doi.org/10.3969/j.issn.1007-2179.2006.01.007

Lu, G. S., Liu, L. \& Sun, J. C. (2005). Study on the evaluation of scientific research efficiency of universities directly under the ministry of education. Journal of Xi'an Jiaotong University (Social Sciences), 25(2), 75 79. http://dx.doi.org/10.3969/j.issn.1008-245X.2005.02.014

Lv, G. Q., Zeng, G., \& Gu, N. N. (2014). Literature review of regional innovation network: an economic geographical perspective. Economic Geography, 34(2), 1-7. http://dx.doi.org/10.3969/j.issn.10008462.2014.02.001

Ruggiero, J., Miner, J., \& Blanchard, L. (2002). Measuring equity of educational outcomes in the presence of 
Li, Li, Yang, Ma / Empirical study of the knowledge innovation efficiency of universities in different regions ...

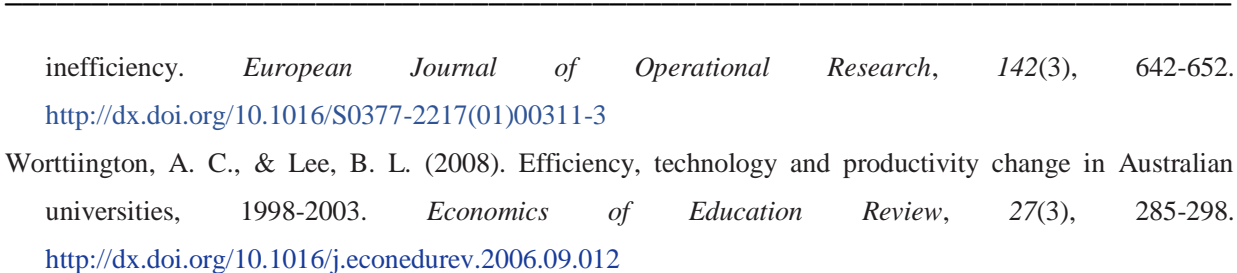

Wu, J. \& Si, Q. F. (2008). Knowledge innovation and transfer: A study on output efficiency of academic papers in colleges and universities. Science of Science and Management of S.\& T., 29(3), 95-98. 